\title{
BMJ Open Determinants of neonatal mortality among preterm births in Black Lion Specialized Hospital, Addis Ababa, Ethiopia: a case-cohort study
}

\author{
Yared Asmare Aynalem (10 , ${ }^{1}$ Hussien Mekonen, ${ }^{2}$ Kenean Getaneh, ${ }^{3}$ \\ Tadesse Yirga (D) , ${ }^{4}$ Ermias Sisay Chanie (D) , ${ }^{5}$ Wubet Alebachew Bayih (D), \\ Wondimeneh Shibabaw Shiferaw (D) ${ }^{1}$
}

To cite: Aynalem YA, Mekonen H, Getaneh K, et al. Determinants of neonatal mortality among preterm births in Black Lion Specialized Hospital, Addis Ababa, Ethiopia: a case-cohort study. BMJ Open 2022;12:e043509. doi:10.1136/ bmjopen-2020-043509

- Prepublication history for this paper is available online. To view these files, please visit the journal online (http://dx.doi. org/10.1136/bmjopen-2020043509).

Received 08 August 2020 Accepted 07 January 2022

Check for updates

(C) Author(s) (or their employer(s)) 2022. Re-use permitted under CC BY-NC. No commercial re-use. See rights and permissions. Published by BMJ.

${ }^{1}$ Debre Berhan University, Debre Berhan, Amhara, Ethiopia

${ }^{2}$ Addis Ababa University, College of Health Sciences, Addis Ababa, Addis Ababa, Ethiopia

${ }^{3}$ Woldia University, Woldia, Amhara, Ethiopia

${ }^{4}$ Debre Markos University, Debre Markos, Amhara, Ethiopia

${ }^{5}$ Pediatrics and Neonatal

Nursing, Debre Tabor University, Debre Tabor, Ethiopia

Correspondence to Yared Asmare Aynalem; yaredasmare123@gmail.com

\section{ABSTRACT}

Background Preterm neonatal death is a global burden in both developed and developing countries. In Ethiopia, it is the first and fourth cause of newborn and under- 5 deaths, respectively. From 2015 to present, the government of Ethiopia showed its effort to improve the survival of neonates, mainly preterm births, through the inclusion of high-impact lifesaving neonatal interventions. Despite these efforts, the cause of preterm neonatal death is still not reduced as expected. Therefore, this study aimed to identify determinants of preterm neonatal mortality.

Methods An institution-based retrospective case-cohort study was conducted among a cohort of preterm neonates who were born between March 2013 and February 2018. A total of 170 cases were considered when the neonates died during the retrospective follow-up period, which was confirmed by reviewing a medical death certificate. Controls were 404 randomly selected charts of neonates who survived the neonatal period. Data were collected from patient charts using a data extraction tool, entered using EpiData V.3.1 and analysed using STATA V.14. Finally, a multivariate logistic regression analysis was performed, and goodness of fit of the final model was tested using the likelihood ratio test. Statistical significance was declared at a p value of $\leq 0.05$.

Results In this study, the overall incidence rate of mortality was 39.1 (95\% Cl: 33.6 to 45.4) per 1000 neonate-days. Maternal diabetes mellitus (adjusted OR (AOR): $2.3(95 \% \mathrm{Cl}$ : 1.4 to 3.6)), neonatal sepsis (AOR: 1.6 (95\% Cl: 1.1 to 2.4$)$ ), respiratory distress (AOR: 1.5 (95\% Cl: 1.1 to 2.3$)$ ), extreme prematurity (AOR: 2.9 (95\% Cl: 1.61 to 5.11)), low Apgar score (AOR: 3.1 (95\% Cl: 1.79 to 5.05)) and premature rupture of membranes (AOR: 2.3 (95\% Cl: 1.8 to 3.5)) were found to be predictors.

Conclusion In this study, the overall incidence was found to be high. Premature rupture of membranes, maternal diabetes mellitus, sepsis, respiratory distress, extreme prematurity and low Apgar score were found to be predictors of neonatal mortality. Therefore, it should be better to give special attention to patients with significantly associated factors.

\section{BACKGROUND}

The neonatal period is the first 4 weeks of a child's life in which changes are very rapid. ${ }^{1}$
Strengths and limitations of this study

- Standard data extraction tool which is adopted from neonatal intensive care unit guidelines of the Federal Ministry of Health of Ethiopia.

- Long-term follow-up period, which we can draw observational conclusions.

- Some variables were not accessible in the medical records and, therefore, were not included in this study since it is the inherent limitation of the historical follow-up study.

- Study participants whose charts were not available and charts did not have outcome variables were not included in the study, which may underestimate the result.

This period is the most risky time for child survival, in which marked physiological transitions occur in all organ systems, and they learn to respond to many forms of external stimuli. ${ }^{23}$ Preterm neonates are born before the vital organs are well established. Therefore, they faced a variety of challenges which predispose to: feeding difficulty; altered body temperature; apnoea and bradycardia; complicated nutritional, fluid and electrolyte management; sepsis and hypoglycaemia. ${ }^{4}$

The rate of preterm birth and death varies all over the globe. In 2016, more than 15 million babies were born before 37 weeks of gestational age (GA). From this, $60 \%-85 \%$ are found in Africa and South Asia, which hold the high mortality rate. ${ }^{45}$ This indicates that it is a public health problem, particularly in developing countries. ${ }^{467}$

Globally, there are different policies, strategies, and programmes that work on the prevention and reduction of death. ${ }^{89}$ Despite this, it remains the leading cause of newborn death and the leading cause of under-5 deaths in the world. ${ }^{10}$ The global community has also 
shown good progress in decreasing under-5 deaths from predictors such as pneumonia, diarrhoea and measles. However, preterm birth asphyxia and neonatal sepsis remain the leading causes of death. ${ }^{11}{ }^{12}$ It is also associated with intrauterine growth restriction, conditions that lead to asphyxia, such as early-onset sepsis, and medical and gynaecological problems of the mother, such as multiple pregnancies, hypertension and HIV/AIDS..$^{13} 14$

In Ethiopia, approximately 89000 deaths per year occur in the neonatal period, accounting for $44 \%$ of all under-5 deaths, and preterm birth is the leading cause of death. ${ }^{6712}$ According to a report by the Federal Ministry of Health of Ethiopia and different studies, preterm birth is the first cause of neonatal mortality and the fourth cause of under-5 mortality. ${ }^{12} 1415$ Additionally, determinants are not well recognised in Ethiopia primarily at the institutional level or in the study area, but few studies have reported causes such as sepsis, asphyxia, preterm birth and congenital malformations. ${ }^{6} 121516$ Most studies in Ethiopia also try to investigate the predictors of neonatal mortality, ${ }^{6} 121516$ but little is known about the determinants of preterm neonatal mortality, particularly in this study area. Therefore, this study aimed to identify the determinants of preterm neonatal mortality in neonatal intensive care units (NICUs) of the Black Lion Specialized Hospital in Addis Ababa, Ethiopia.

\section{METHODS AND MATERIALS}

\section{Study design, area, period, population and eligibility criteria}

An institutional-based case-cohort study was conducted in the Black Lion Specialized Hospital of Addis Ababa, Ethiopia from March to 1 April 2018. Preterm is defined as babies born alive before 37 weeks of pregnancy is completed. ${ }^{1}$ The study was conducted in Addis Ababa, the capital city of Ethiopia at the Black Lion Specialized Hospital. Addis Ababa has 10 subcities in which the city lies at an altitude of $7546 \mathrm{ft}(2300 \mathrm{~m})$. It has 12 governmental and 9 non-governmental hospitals. The Black Lion Specialized Hospital is among the governmental hospitals which has 600 beds in medical, gynaecological and obstetrics, surgical, paediatrics, emergency and outpatient department. It has also seven X-ray, nine surgical and three laboratory diagnostic rooms. It offers diagnosis and treatment for approximately $370000-400$ 000 patients per year, and there are around 715 nurses and 237 physicians. The NICU ward of the hospital is able to accommodate a maximum of 60 patients with an average of 20-40 patients in daily admission. There are on average 5000-6000 annual admissions of neonates and $75 \%$ of admissions are from referral of different birth centres. Many referrals consist of premature and low birthweight neonates. An average of 1000 premature neonates were admitted to the NICU per year over the past 5 years. From a total of $25000 / 5$-year NICU admissions, premature neonates account $20 \%$ (5000) of the neonatal admissions per 5 years. The NICU ward of the Black Lion Specialized Hospital is able to accommodate a maximum of 60 patients with an average of 20-40 patients in daily admission (see figure 1).

\section{Populations}

All preterm newborns admitted in the Black Lion Specialized Hospital including those who come from other facilities by referral were the source population. Preterm births admitted in the Black Lion Specialized Hospital that fulfilled the inclusion criteria were the study population.

\section{Cases}

Cases were considered when preterm neonates died at the NICU, which was confirmed by reviewing a medical diagnosis in the hospital. Those who were born alive from 1 January 2013 to 28 February 2018 and died within 28 days of birth were considered as a case.

\section{Controls}

Those preterm neonates (less than 37 weeks) recorded as alive during the follow-up time. Either last menstrual period or ultrasounds were used to estimate the GA from the chart.

Cases and controls were identified through record review after physician diagnosis and using prepared clinical checklists.

\section{Eligibility criteria}

All preterm babies with card documentation in the previous 5 years (from 1 January 2013 to 30 February 2018) were recruited, while those with incomplete cards were excluded. Cases were included when the born alive preterm neonate's chart has date of admission, discharge and medical death of physician diagnosis in the hospital. Those neonates whose charts had incomplete records and were not available at the time of data collection were excluded.

\section{Controls}

Those preterm neonates (less than 37 weeks) recorded as alive during the follow-up time were also included in this study.

\section{Sample size determination and sampling procedure}

The sample size was determined using the Epi Info V.7.0.1 double population proportion exposure difference formula by considering major determinant variables (antenatal care (ANC) visit, place of delivery, ANC visit frequency and breast feeding within the first hour of delivery) from a study performed in North Shoa. ${ }^{17} \mathrm{We}$ considered ANC visit as an independent predictor since it gives a maximum sample size compared with other exposure variables. From that study, the proportion of women among controls with ANC visits less than three was $49.4 \%$, and among cases with ANC visits less than three was $63.9 \% .{ }^{17}$ Finally, by using one to two ratios of the case to control (1:2), a 95\% level of confidence, with a power of $80 \%$ and adding a $10 \%$ non-response rate, the total sample size was 574 (170 cases and 404 controls). 


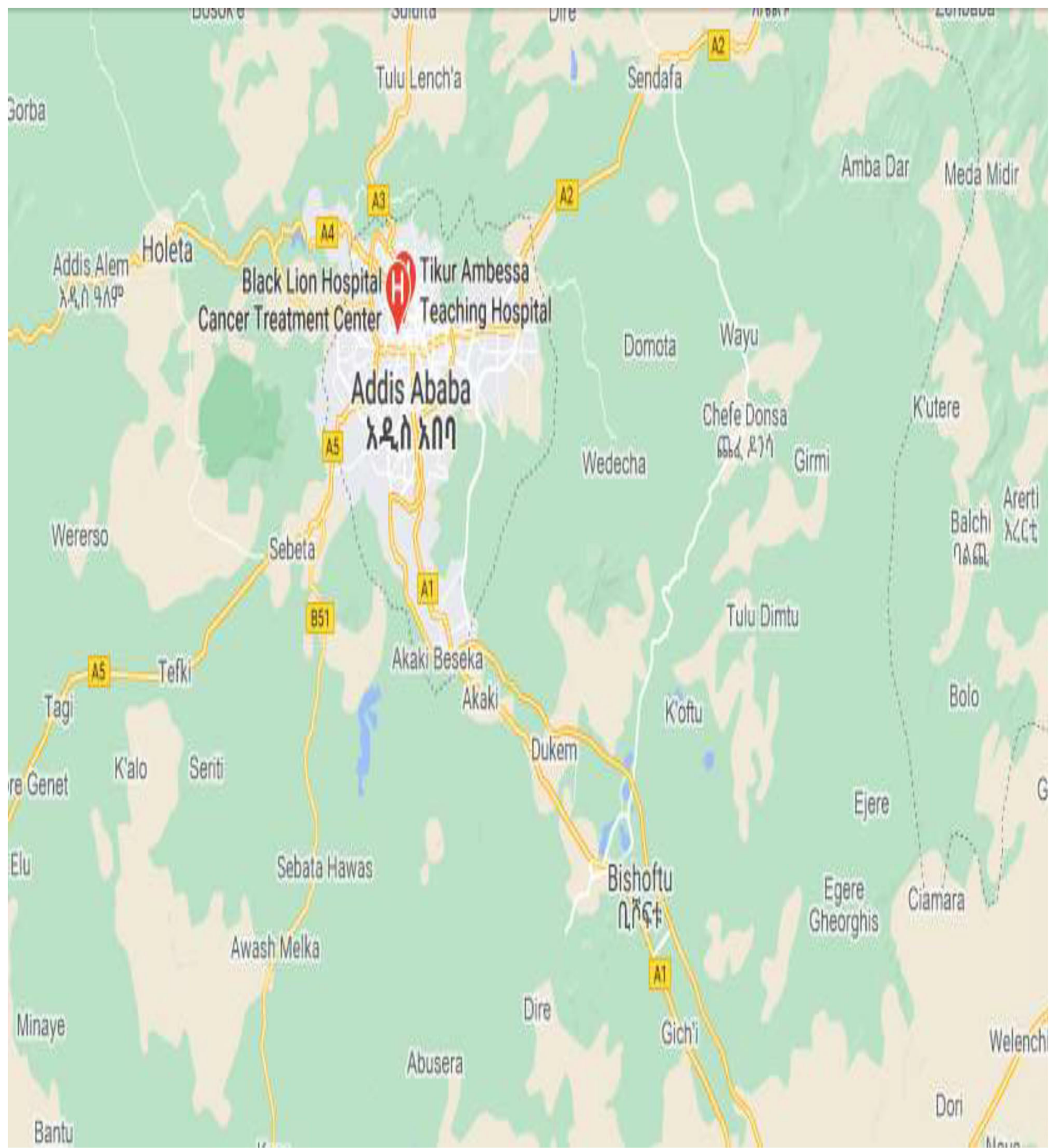

Figure 1 Geographical location of the study area.

\section{Sampling technique and procedure}

A simple random sampling for cases and controls was used separately as follows: there were 5000 preterm neonates who were admitted to the NICU in the past 5 years (from 1 January 2013 to 30 February 2018). Of the preterm neonates who were followed in the cohort, 210 died. Of those, 170 cases were included using computer-generated simple random sampling. The remaining 4790 preterm neonates were registered as alive during the follow-up period. Of those, 750 were referred to other health institutions, and 4040 were admitted to the NICU. Therefore, we selected 404 controls using computer-generated simple random sampling.

\section{Variables of the study}

Dependent variable

Preterm neonatal death, which was dichotomised as 1 if neonates had died and 0 if not.

\section{Independent variable}

In the current study, four categorical independent variables were collected and analysed. These factors were sociodemographic factors (neonatal: age at admission, GA, sex, weight of neonate, date of NICU admission and discharge; maternal: age, residency), gynaecologicalobstetric-related factors (such as having ANC follow-up, gravidity, parity, mode of delivery, multiple pregnancies, 
premature rupture of membranes (PROM), preeclampsia, abruption placenta, breastfeeding initiation), medical disorders of the mother (such as hypertension, diabetes mellitus (DM), HIV/AIDS, anaemia), and neonatal outcome conditions (such as Apgar score, respiratory distress (RD), sepsis, jaundice, hypothermia, perinatal asphyxia (PNA).

\section{Data collection tools and procedures}

A questionnaire was prepared by reviewing different kinds of literature and other checklists related to risk factors of neonatal mortality. Most questions were adapted from questionnaires used in other studies to investigate risk factors for neonatal sepsis. ${ }^{17-20}$ Then, the designed questionnaires were changed from English to Amharic and back to English to check the consistency of the questionnaire. Data were collected through record review using pretested structured checklists. Rechecking on $5 \%$ of participants was made each day to confirm the reliability of the data collected. Data were collected by four trained BSc nurses, and they were supervised by one BSc nurse with previous experience in data collection.

\section{Data quality control measures}

It was assured by designing proper data abstraction tools. The checklist was evaluated by experienced researchers. The data collection instrument was pretested on $5 \%$ of the sample size at Yekatit 12 Hospital to avoid information contamination. Language clarity, appropriateness of data collection tools, estimated time to completion and the necessary amendments were considered based on the pretest. Intensive training was given concerning the data abstraction tool and data collection process for both data collectors and supervisors. During the data collection time, close supervision and monitoring were performed.

\section{Data processing and analysis}

Data were checked for completeness and consistency. They were cleaned, coded and entered using EpiData V.3.1 and exported to STATA software V.14 for analysis. Descriptive statistics were used to describe the study population concerning relevant variables. ORs were used to assess the strength of the relationship between the independent variable and outcome variable. Variables that had an association in the bivariate $(\mathrm{p}<0.25)$ were entered and analysed by a multivariate logistic regression model to identify the independent effect of independent variables on the dependent variable. In the final multivariate models, the level of multicollinearity was checked and fitted using variance inflation factor and tolerance and found within a tolerable range (all variable values $>1$ and $<5$ ) and tolerance (all variable values $>0.2$ ). Goodness of fit and Hosmer-Lemeshow were checked and fitted for the data with a $p$ value of 0.23 . In a multivariable regression analysis, a $p$ value less than 0.05 was considered statistically significant.
Table 1 Sociodemographic characteristics of premature neonates in Black Lion Specialized Hospital, Addis Ababa, Ethiopia, 2018

\begin{tabular}{lllcc}
\hline \multirow{2}{*}{ Covariates } & Category & Total (\%) & Case (\%) & Control (\%) \\
\hline Sex & Female & $272(47.6)$ & $60(35.3)$ & $212(52.9)$ \\
& Male & $299(52.4)$ & $110(64.7)$ & $189(47.1)$ \\
GA & $26-<28$ & 65 & $25(14.7)$ & $100(24.9)$ \\
& $28-<32$ & 121 & $60(35.3)$ & $105(26.3)$ \\
\multirow{2}{*}{ Maternal age } & $<20$ & $61(10.9)$ & $22(12.9)$ & $39(9.7)$ \\
& $20-34$ & $426(74.6)$ & $107(62.9)$ & $319(79.6)$ \\
\cline { 4 - 5 } & $>34$ & $84(14.7)$ & $41(24.1)$ & $43(10.7)$ \\
\hline Residency & Rural & $188(32.9)$ & $92(54.1)$ & $111(27.7)$ \\
& Urban & $383(67.1)$ & $78(45.9)$ & $291(72.3)$ \\
\hline
\end{tabular}

GA, gestational age.

\section{RESULTS}

Sociodemographic characteristics of the mothers and neonates

From 574 preterm neonate charts reviewed, 571 (98.6\%) records met the enrolment criteria. Approximately 299 $(52.36 \%)$ of the study participants were male, and the majority of the $382(66.90 \%)$ were from urban areas. Neonates in the early neonatal period accounted for $275(48.2 \%)$ of the study participants. The mean age of mothers was $28 \pm 5.42$ years old. The majority of them, 426 $(74.61 \%)$, belong to the age group of 20-35 years. The mean age of the cohort at the time of admission to the NICU was $3 \pm 3.72$ days. The mean weight was also found to be $1837.01 \pm 518.94 \mathrm{~g}$ (table 1$)$.

\section{Maternal and pregnancy characteristics}

Among the total mothers enrolled in the study, 310 (54.29\%) of the mothers had given birth through spontaneous vaginal delivery, and $249(43.61 \%)$ of them had caesarean section both in cases and controls. A total of $30.6 \%$ of cases and $42.3 \%$ of controls were born from mothers with pre-eclampsia. Preterm newborns whose mothers had a PROM in both the control and case groups accounted for $34.1 \%$ and $28.9 \%$, respectively. Additionally, $84.2 \%$ of cases and $69.4 \%$ of controls were born from mothers with a full ANC follow-up history. Regarding pregnancy-related complications, 76 (13.3\%), 56 (9.8\%), and $45(7.9 \%)$ had HIV/AIDS, gestational DM (GDM) and anaemia, respectively (table 2 ).

\section{Common diagnosis of preterm neonates}

The common medical problems identified among admitted neonates during the study period were low Apgar score (first minute Apgar score less than 7, 437; $76.5 \%)$, hypothermia $(391 ; 68.5 \%)$, RD (352; 61.6\%) and neonatal sepsis $(323 ; 56.6 \%)$ in both cases and controls. The other common causes of admissions were 
Table 2 Maternal and pregnancy characteristics in Black Lion Specialized Hospital, Addis Ababa, Ethiopia, 2018

\begin{tabular}{|c|c|c|c|c|}
\hline \multirow[b]{2}{*}{ Covariates } & \multirow[b]{2}{*}{ Category } & \multirow[b]{2}{*}{ Total (\%) } & \multicolumn{2}{|l|}{ Status } \\
\hline & & & Case (\%) & $\begin{array}{l}\text { Control } \\
\text { (\%) }\end{array}$ \\
\hline \multirow[t]{3}{*}{$\begin{array}{l}\text { Mode of } \\
\text { delivery }\end{array}$} & $\begin{array}{l}\text { Caesarean } \\
\text { section }\end{array}$ & $249(43.6)$ & $87(51.2)$ & $162(40.4)$ \\
\hline & Spontaneous & 310 (54.3) & 79 (46.8) & $231(57.6)$ \\
\hline & Instrumental & 12 & 4 & 8 \\
\hline \multirow[t]{2}{*}{ Pre-eclampsia } & Yes & $175(30.6)$ & $72(42.3)$ & $103(25.7)$ \\
\hline & No & 396 (69.3) & $98(57.7)$ & $298(74.3)$ \\
\hline \multirow{2}{*}{$\begin{array}{l}\text { Premature } \\
\text { rupture of } \\
\text { membranes }\end{array}$} & Yes & 165 (28.9) & $58(34.1)$ & $107(26.7)$ \\
\hline & No & $406(71.1)$ & $112(65.9)$ & 294 (73.3) \\
\hline \multirow[t]{2}{*}{ ANC follow-up } & Yes & $481(84.2)$ & $118(69.4)$ & $363(90.5)$ \\
\hline & No & $90(15.8)$ & $52(30.6)$ & $38(9.5)$ \\
\hline \multirow[t]{2}{*}{ Parity } & $<2$ & 439 (76.9) & $125(73.5)$ & $314(78.3)$ \\
\hline & $\geq 2$ & $132(23.1)$ & 45 (26.5) & $87(21.7)$ \\
\hline \multirow[t]{2}{*}{ Gravidity } & $<2$ & $375(65)$ & $101(59.4)$ & 274 (68.3) \\
\hline & $\geq 2$ & 196 (34.3) & $69(40.6)$ & $127(31.7)$ \\
\hline \multirow{2}{*}{$\begin{array}{l}\text { Multiple } \\
\text { pregnancies }\end{array}$} & Yes & $220(38.5)$ & 82 (48.2) & $138(34.4)$ \\
\hline & No & $351(61.5)$ & 88 (51.8) & $263(65.6)$ \\
\hline \multirow[t]{2}{*}{ HIV/AIDS } & Reactive & $76(13.3)$ & 35 (20.6) & $41(10.2)$ \\
\hline & None reactive & 495 (86.7) & $135(79.4)$ & $360(89.8)$ \\
\hline \multirow[t]{2}{*}{ DM } & Yes & $56(9.8)$ & $34(20)$ & $22(5.5)$ \\
\hline & No & 515 (90.2) & 136(80) & $379(94.5)$ \\
\hline \multirow[t]{2}{*}{ Anaemia } & Yes & 45 (7.9) & $23(13.5)$ & $22(5.5)$ \\
\hline & No & $526(92.1)$ & $147(86.5)$ & $379(94.5)$ \\
\hline
\end{tabular}

ANC, antenatal care; DM, diabetes mellitus.

jaundice, hypoglycaemia, PNA, congenital heart defect and anaemia (table 3 ).

\section{Incidence of death among premature neonates}

Preterm neonates who were admitted to the NICU were followed up from 0 to 28 days. The incidence rate of preterm neonatal mortality was 39.1 deaths per 1000 person-days (95\% CI: 33.6 to 45.4 ) with a total follow-up of 4354 person-days. The overall median length of stay for neonates under the study was 20 days (95\% CI: 1.2 to 26.1).

\section{Determinants of preterm neonatal mortality}

The relationship between the variables and the risk of mortality was analysed using a logistic regression model. The logistic regression model in table 4 shows that maternal factors such as age $\geq 34$ years, rural setting, having ANC follow-up, multiple pregnancies, PROM, preeclampsia, HIV/AIDS, anaemia, congestive heart failure (CHF), oligohydramnios/polyhydramnios and neonatal factors such as being male, GA, weight, sepsis, RD, hypoglycaemia, jaundice, hypothermia, first minute and fifth minute Apgar scores and breastfeed initiation time were statistically significant $(\mathrm{p}<0.05)$ predictors of neonatal
Table 3 Common medical diagnoses of preterm neonates in Black Lion Specialized Hospital, Addis Ababa, Ethiopia, 2018

\begin{tabular}{llrcr}
\hline & & & \multicolumn{2}{l}{ Status } \\
\cline { 5 - 5 } Covariant & Category & Total (\%) & Case (\%) & Control (\%) \\
\hline RD & No & $219(38.3)$ & $36(21.2)$ & $183(45.6)$ \\
& Yes & $352(61.6)$ & $134(78)$ & $218(54.4)$ \\
Jaundice & No & $369(64.6)$ & $92(54.1)$ & $277(69.1)$ \\
& Yes & $202(35.4)$ & $78(45.9)$ & $124(30.9)$ \\
1st minute & $<7$ & $437(76.5)$ & $154(90.6)$ & $283(70.5)$ \\
Apgar score & $>7$ & $134(23.5)$ & 16 & $118(29.5)$ \\
Hypothermia & No & $180(31.5)$ & $31(18.2)$ & $149(37.2)$ \\
& Yes & $391(68.5)$ & $139(81.8)$ & $252(62.8)$ \\
Sepsis & No & $247(43.3)$ & $44(25.9)$ & $203(50.6)$ \\
& Yes & $323(56.6)$ & $126(74.1)$ & $198(49.4)$ \\
Hypoglycaemia & No & $465(81.4)$ & $121(71.2)$ & $344(85.8)$ \\
& Yes & $106(18.6)$ & $49(28.8)$ & $57(14.2)$ \\
CHD & No & $506(88.6)$ & $146(85.9)$ & $360(89.8)$ \\
& Yes & $65(11.4)$ & $24(14.1)$ & $41(10.2)$ \\
\hline
\end{tabular}

$\mathrm{CHD}$, congenital heart defect; $\mathrm{RD}$, respiratory distress.

mortality in the bivariate analysis. Moreover, to identify independent predictors of mortality, a multivariable logistic regression analysis was performed for all predictors found to be a significant predictor in the bivariate analysis. Nonetheless, PROM, residency, DM, neonatal sex, GA, first minute Apgar score, RD and sepsis were found to be strong predictors of mortality in the multivariate analysis. The odds of preterm neonates' death admitted to the NICU from mothers with DM were 2.3 times more likely than their counterparts (adjusted OR (AOR): 2.9 (95\% CI: 1.4 to 3.6)).

The likelihood of death among preterm neonates with $\mathrm{RD}$ increases by $50 \%$ compared with their counterparts (AOR: 1.5 (95\% CI: 1.03 to 2.3)). Likewise, neonates whose first minute Apgar score was less than 7 were three times more likely to die than neonates whose first minute Apgar score was greater than 7 (AOR: 3.1 (95\% CI: 1.8 to 5.1)).

A preterm neonate's death who had sepsis at the time of admission was also increased by $60 \%$ (AOR: $1.6(95 \%$ CI: 1.11 to 2.4 )). The risk of death was 1.5 times (AOR: 1.5 (95\% CI: 1.2 to 2.1)) higher in patients who were male than female (table 4).

\section{DISCUSSION}

Preterm birth remains a significant cause of morbidity and mortality among preterm neonates and children. This study was conducted to identify determinants of preterm neonatal mortality in the Black Lion Specialized Hospital. At the end of follow-up, the overall incidence of mortality was found to be 39.1 deaths per 1000 person-days, which exceeds both reports by Ethiopia demographic and 
Table 4 Results of risk of preterm neonatal death in the bivariate and multivariate logistic regression analyses in Black Lion Specialized Hospital, Addis Ababa, Ethiopia, 2018

\begin{tabular}{|c|c|c|c|}
\hline Predictor & Category & COR (95\% CI) & AOR $(95 \% \mathrm{Cl})$ \\
\hline \multirow[t]{3}{*}{ Mother's age } & $<20$ & 1.5 (0.9 to 2.4$)$ & $1.1(0.67$ to 1.9$)$ \\
\hline & $20-34$ & 1 & \\
\hline & $\geq 34$ & $1.7(1.2 \text { to } 2.4)^{\star}$ & 0.9 (0.6 to 1.3$)$ \\
\hline \multirow[t]{2}{*}{ Sex } & Female & 1 & \\
\hline & Male & $1.7(1.2 \text { to } 2.3)^{\star \star}$ & $1.5(1.1 \text { to } 2.1)^{\star}$ \\
\hline \multirow{2}{*}{$\begin{array}{l}\text { Multiple } \\
\text { pregnancies }\end{array}$} & Yes & $1.6(1.1 \text { to } 2.1)^{\star}$ & 1.1 (0.9 to 1.6$)$ \\
\hline & No & 1 & \\
\hline \multirow[t]{2}{*}{ PROM } & Yes & $1.5(1.1 \text { to } 2.0)^{\star}$ & $2.3(1.8 \text { to } 3.5)^{\star \star}$ \\
\hline & No & 1 & \\
\hline \multirow[t]{2}{*}{ Pre-eclampsia } & Yes & $1.6(1.2 \text { to } 2.2)^{\star \star}$ & 0.9 (0.6 to 1.2$)$ \\
\hline & No & 1 & \\
\hline \multirow[t]{2}{*}{ HIV/AIDS } & Reactive & $1.9(1.3 \text { to } 2.7)^{\star *}$ & 1.5 (0.9 to 2.5$)$ \\
\hline & $\begin{array}{l}\text { None } \\
\text { reactive }\end{array}$ & 1 & \\
\hline \multirow[t]{2}{*}{ DM } & Yes & $2.4(1.6 \text { to } 3.5)^{\star *}$ & $2.9(1.4 \text { to } 3.6)^{* *}$ \\
\hline & No & 1 & \\
\hline \multirow[t]{2}{*}{$\mathrm{RD}$} & Yes & $2.3(1.6 \text { to } 3.4)^{\star \star}$ & $1.5(1.0 \text { to } 2.3)^{\star \star}$ \\
\hline & No & 1 & \\
\hline \multirow[t]{2}{*}{ Sepsis } & Yes & $2.2(1.5 \text { to } 3.1)^{\star \star \star}$ & $1.6(1.1 \text { to } 2.4)^{\star \star}$ \\
\hline & No & 1 & \\
\hline \multirow[t]{2}{*}{ Hypoglycaemia } & Yes & $1.6(1.2 \text { to } 2.3)^{\star \star}$ & 0.7 (0.5 to 1.1$)$ \\
\hline & No & 1 & \\
\hline \multirow[t]{3}{*}{ GA } & $26-28$ & $6.3(3.9 \text { to } 10.2)^{\star \star \star}$ & $2.8(1.6 \text { to } 5.1)^{\star \star \star}$ \\
\hline & 28-32 & $1.9(1.4 \text { to } 2.7)^{\star \star \star}$ & 0.9 (0.6 to 1.4$)$ \\
\hline & $32-37$ & 1 & \\
\hline \multirow{2}{*}{$\begin{array}{l}\text { 1st minute } \\
\text { Apgar score }\end{array}$} & $<7$ & $3.2(1.9 \text { to } 5.4)^{\star}$ & $3.1(1.9 \text { to } 5.0)^{\star}$ \\
\hline & $\geq 7$ & 1 & \\
\hline
\end{tabular}

*Significant $(p<0.05),{ }^{* *}$ significant $(p<0.01),{ }^{* * *}$ significant $(p<0.001)$. AOR, adjusted OR; COR, crude OR; DM, diabetes mellitus; GA, gestational age; PROM, premature rupture of membranes; RD, respiratory distress.

health survey (EDHS) (29\% per 1000 person-days ${ }^{21}$ and China, ${ }^{22}$ but lower than a study in Jordan. ${ }^{23}$ Similarly, the current finding is higher than a study conducted in Ethiopia, Tigray region. ${ }^{15}$ This marked that the difference might be attributed to several factors, such as care difference, in which developed countries might be better equipped with skilled professionals, support personnel, and equipment to perform neonatal resuscitation, and evaluate and provide postnatal care of a newborn.

In this study, being male was a significant determinant of preterm neonatal mortality. Male neonates were one and half times more likely to die (AOR: 1.5 (95\% CI: 1.1 to 2.1)), in agreement with another study conducted in the world. ${ }^{24-26}$ It might be due to the fact that male neonates have been reported to have a higher level of circulating testosterone than female neonates. This difference might be associated with differences in pulmonary biomechanics and vascular development that lead to increased respiratory and neurological morbidity among preterm male neonates. ${ }^{27}$

PROM was significantly associated with the risk of preterm neonatal death. Explicitly, neonates born from women with the duration of labour after rupture of the membrane greater than 18 hours were approximately two and half times more likely to suffer from death compared with those neonates born from women with the duration of rupture of the membrane less than 12 hours. This finding is comparable with studies conducted in Ethiopia $^{26}{ }^{28}$ and Kenya. ${ }^{29}{ }^{30}$ These findings may be due to the fact that the birth canal is populated with aerobic and anaerobic pathogens that might cause ascending amniotic fluid infection and colonisation of the neonate at birth.

Moreover, this study showed that neonatal sepsis was one risk factor for mortality. Preterm neonatal mortality among neonates with sepsis was two times more likely as compared with those who did not have sepsis. This finding is supported by a result from developed and developing countries..$^{261-34}$ The possible reason might be most of the premature neonates were born with PROM. Other possible explanations might be immature immunity, different procedures and the mode of delivery, which might have its contribution.

This argument also justifies the increased odds of death among neonates born with RD. Those neonates born with RD were nearly one and half times more likely to suffer from neonatal death compared with those without RD. Consistent results have been recorded in our country and other studies. ${ }^{16}{ }^{34-36}$ This may be due to lung immaturity (lack of adequate surfactant substance which prevents collapse of alveoli at the end of expiration) and maternal factors like having DM and PROM, which may increase alveolar surface tension. Additionally, premature neonates may be using up their pulmonary reserve and may eventually develop respiratory failure.

This study also assesses whether maternal DM has an effect on mortality of newborns. This study revealed that preterm neonatal mortality among mothers with DM was three times more likely compared with those neonates born from mothers without DM. This finding is in line with the findings from studies conducted in different countries. ${ }^{35}$ This might be because premature neonates born from women with DM may have abundant glucose stored in the form of glycogen and fat but develop hypoglycaemia because of hyperinsulinaemia induced by maternal and fetal hyperglycaemia.

The current finding also noted that the likelihood of preterm neonatal mortality was higher among neonates born less than 28 weeks of GA. Neonates born less than 28 weeks of GA were 1.6 times more likely to die as compared with neonates born between 32 and 37 weeks of GA. This is supported by a previous study done in different countries. 3536 
Another determinant factor was the first minute Apgar score less than 7 . The odds of preterm neonatal mortality were three times higher in neonates with first minute Apgar score less than 7 compared with neonates with greater than 7 . This finding was supported by studies conducted in Ethiopia ${ }^{31} 3638$ and other countries. ${ }^{34} 35$ This might be because of delays in the identification of newborn complications, poor management and lack of postnatal care in our study setting. Therefore, this study implies that professionals working in NICUs could be motivated towards care to reduce neonatal mortality including effective ANC to reduce maternal GDM. Administration of antibiotics in the peripartum period should be emphasised to reduce PROM and administration of corticosteroids to reduce $\mathrm{RD}$ before reaching the NICU. The current finding has the following limitations: first, selection bias may have been introduced during secondary data collection because patients with incomplete records were excluded. Second, since the data were collected from secondary source, some important predictors such as socioeconomic factors like nutritional status of mother, educational level and birth interval might be missed.

\section{Conclusion}

In the current study, the overall incidence rate was found to be high. The multivariate logistic regression analysis showed that the main determinants of preterm neonatal mortality were found to be male sex, maternal DM, PROM, neonatal sepsis, RD, GA less than 28 weeks, and low first minute and fifth minute Apgar scores. Therefore, it would be important to give due attention for preterm neonates diagnosed with sepsis and RD, with GA less than 28 weeks, and with low first minute and fifth minute Apgar scores; and strengthen screening of GDM.

Acknowledgements We would like to thank Addis Ababa University, School of Health Sciences for ethical clearance. We would also like to acknowledge the study participants, data collectors and the supervisor. Our gratitude also goes to Dr Ryan Bell (CEO and Chief Editor Excision Editing) who has made an extensive editing in our manuscript.

Contributors YAA contributed to the conception, study design, data acquisition, data interpretation and writing of the original article. WSS, TY, HM and KG were involved in the planning, conduct and reporting of the work in the paper. YAA, ESC and WAB contributed to the conception and design, data acquisition, critical revision and data interpretation. All authors participated in the study design, interpretation of the data and writing of the paper, and made final approval of the paper.

Funding The authors have not declared a specific grant for this research from any funding agency in the public, commercial or not-for-profit sectors.

Map disclaimer The inclusion of any map (including the depiction of any boundaries therein), or of any geographic or locational reference, does not imply the expression of any opinion whatsoever on the part of BMJ concerning the legal status of any country, territory, jurisdiction or area or of its authorities. Any such expression remains solely that of the relevant source and is not endorsed by BMJ. Maps are provided without any warranty of any kind, either express or implied.

Competing interests None declared.

Patient and public involvement Patients and/or the public were not involved in the design, or conduct, or reporting, or dissemination plans of this research.

Patient consent for publication Not required.
Ethics approval A written letter of permission from the research committee of Addis Ababa University, College of Health Sciences was obtained and submitted to TASH. Oral permission was obtained from TASH coordinators. Confidentiality of the patient profiles was ensured throughout the research process.

Provenance and peer review Not commissioned; externally peer reviewed.

Data availability statement The data are accessible from the corresponding author upon reasonable request.

Open access This is an open access article distributed in accordance with the Creative Commons Attribution Non Commercial (CC BY-NC 4.0) license, which permits others to distribute, remix, adapt, build upon this work non-commercially, and license their derivative works on different terms, provided the original work is properly cited, appropriate credit is given, any changes made indicated, and the use is non-commercial. See: http://creativecommons.org/licenses/by-nc/4.0/.

\section{ORCID iDs}

Yared Asmare Aynalem http://orcid.org/0000-0002-3005-2296

Tadesse Yirga http://orcid.org/0000-0002-5475-6183

Ermias Sisay Chanie http://orcid.org/0000-0002-3124-5380

Wubet Alebachew Bayih http://orcid.org/0000-0003-1439-4402

Wondimeneh Shibabaw Shiferaw http://orcid.org/0000-0003-4348-591X

\section{REFERENCES}

1 Alhabdan YA, Albeshr AG, Yenugadhati N, et al. Prevalence of dental caries and associated factors among primary school children: a population-based cross-sectional study in Riyadh, Saudi Arabia. Environ Health Prev Med 2018;23:60.

2 Guerrera G. Neonatal and pediatric healthcare worldwide: a report from UNICEF. Clin Chim Acta 2015;451:4-8.

3 Heron MP. Deaths: leading causes for 2016, 2018.

4 Estimation UNIGfCM. Levels \& trends in child mortality: report 2017: estimates developed by the UN inter-agency group for child mortality estimation. United Nations Children's Fund, 2017.

5 Elmi Farah A, Abbas AH, Tahir Ahmed A. Trends of admission and predictors of neonatal mortality: a hospital based retrospective cohort study in Somali region of Ethiopia. PLoS One 2018;13:e0203314.

6 Andargie G, Berhane Y, Worku A, et al. Predictors of perinatal mortality in rural population of northwest Ethiopia: a prospective longitudinal study. BMC Public Health 2013;13:168.

7 Ethiopia Central Statistical AgencyMacro O. Ethiopia demographic and health survey. Addis Ababa: Central Statistical Agency, 2016.

8 Desa U. Transforming our world: the 2030 agenda for sustainable development, 2016.

9 Child EWE. The global strategy for women's, children's and adolescents health. New York, NY: Every Woman Every Child, 2015.

10 Liu L, Oza S, Hogan D, et al. Global, regional, and national causes of under-5 mortality in 2000-15: an updated systematic analysis with implications for the sustainable development goals. The Lancet 2016;388:3027-35.

11 Hug L, Alexander M, You D, et al. National, regional, and global levels and trends in neonatal mortality between 1990 and 2017, with scenario-based projections to 2030: a systematic analysis. Lancet Glob Health 2019;7: 710-20.

12 Assefa N, Lakew Y, Belay B, et al. Neonatal mortality and causes of death in Kersa health and demographic surveillance system (Kersa HDSS), Ethiopia, 2008-2013. Matern Health Neonatol Perinatol 2016;2:7.

13 Wayne WD. Biostatics a foundation for analysis in the health sciences. 13th edn. Georgia State University, 2013.

14 Orsido TT, Asseffa NA, Berheto TM. Predictors of neonatal mortality in neonatal intensive care unit at referral hospital in southern Ethiopia: a retrospective cohort study. BMC Preg Child 2019;19:83.

15 Mengesha HG, Wuneh AD, Lerebo WT, et al. Survival of neonates and predictors of their mortality in Tigray region, Northern Ethiopia: prospective cohort study. BMC Pregnancy Childbirth 2016;16:202.

16 Yismaw AE, Gelagay AA, Sisay MM. Survival and predictors among preterm neonates admitted at University of Gondar comprehensive specialized Hospital neonatal intensive care unit, Northwest Ethiopia. Ital J Pediatr 2019;45:4.

17 Kolola T, Ekubay M, Tesfa E, et al. Determinants of neonatal mortality in North Shoa Zone, Amhara Regional State, Ethiopia. PLoS One 2016;11:e0164472.

18 Gebremedhin D, Berhe H, Gebrekirstos K. Risk factors for neonatal sepsis in public hospitals of Mekelle City, North Ethiopia, 2015: unmatched case control study. PLoS One 2016;11:e0154798. 
19 G/Eyesus T, Moges F, Eshetie S, et al. Bacterial etiologic agents causing neonatal sepsis and associated risk factors in Gondar, Northwest Ethiopia. BMC Pediatr 2017;17:137.

20 Weldearegawi B, Melaku YA, Abera SF, et al. Infant mortality and causes of infant deaths in rural Ethiopia: a population-based cohort of 3684 births. BMC Public Health 2015;15:770.

21 EDHS ED. Health survey. Key indicators report, 2016.

$22 \mathrm{Xu} \mathrm{H}$, Dai Q, Xu Y, et al. Time trends and risk factor associated with premature birth and infants deaths due to prematurity in Hubei Province, China from 2001 to 2012. BMC Pregnancy Childbirth 2015;15:329.

23 Abdel Razeq NM, Khader YS, Batieha AM. The incidence, risk factors, and mortality of preterm neonates: a prospective study from Jordan (2012-2013). Turk J Obstet Gynecol 2017;14:28-36.

24 Evans N, Hutchinson J, Simpson JM, et al. Prenatal predictors of mortality in very preterm infants cared for in the Australian and New Zealand neonatal network. Arch Dis Child Fetal Neonatal Ed 2007;92:F34-40.

25 Kibria GMA, Burrowes V, Choudhury A, et al. Determinants of early neonatal mortality in Afghanistan: an analysis of the demographic and health survey 2015. Global Health 2018;14:47.

26 Dagnachew T, Yigeremu M. Survival of preterm neonates and its determinants in teaching hospitals of Addis Ababa university. J Women's Health Care 2019;8:2167-420.

27 Woan J, Lin J, Auerswald C. The health status of street children and youth in low- and middle-income countries: a systematic review of the literature. J Adolesc Health 2013;53:314-21.

28 Workineh Y, Birhanu S, Kerie S, et al. Determinants of premature rupture of membrane in Southern Ethiopia, 2017: case control study design. BMC Res Notes 2018;11:927.

29 Wagura $P$, Wasunna A, Laving A, et al. Prevalence and factors associated with preterm birth at kenyatta national hospital. BMC Pregnancy Childbirth 2018;18:107.
30 Tchirikov M, Schlabritz-Loutsevitch N, Maher J, et al. Mid-trimester preterm premature rupture of membranes (PPROM): etiology, diagnosis, classification, international recommendations of treatment options and outcome. J Perinat Med 2018;46:465-88.

31 Debelew GT, Afework MF, Yalew AW. Determinants and causes of neonatal mortality in Jimma zone, Southwest Ethiopia: a multilevel analysis of prospective follow up study. PLoS One 2014;9:e107184.

32 Mekuriyaw AM, Mihret MS, Yismaw AE. Determinants of preterm birth among women who gave birth in Amhara region referral hospitals, Northern Ethiopia, 2018: institutional based case control study. Int J Pediatr 2020;2020:1-8.

33 Nohr EA, Vaeth $\mathrm{M}$, Bech BH, et al. Maternal obesity and neonatal mortality according to subtypes of preterm birth. Obstet Gynecol 2007;110:1083-90.

34 Babaei H, Dehghan M. Study of causes of neonatal mortality and its related factors in the neonatal intensive care unit of Imam Reza hospital in Kermanshah, Iran during (2014-2016). Int J Pediat 2018;6:7641-9.

35 Yehuala S, Teka Z. Survival analysis of premature infants admitted to neonatal int ensive care unit (NICU) in Northwest Ethiopia using semi-parametric Fr ailty model. J Biomet Biostat 2015;6.

36 Yismaw AE, Tarekegn AA. Proportion and factors of death among preterm neonates admitted in University of Gondar comprehensive specialized hospital neonatal intensive care unit, Northwest Ethiopia. BMC Res Notes 2018;11:867.

37 Persson M, Shah PS, Rusconi F, et al. Association of maternal diabetes with neonatal outcomes of very preterm and very lowbirth-weight infants: an international cohort study. JAMA Pediatr 2018;172:867-75.

38 Wesenu M, Kulkarni S, Tilahun T. Modeling determinants of time-todeath in premature infants admitted to neonatal intensive care unit in Jimma university specialized Hospital. Annals of Data Science 2017;4:361-81. 